\section{Carlos Jorge Ribeiro Silva 30/8/1960 - 27/8/2020}

$>$

Dulce Geraldo

gdulce@quimica.uminho.pt

João Paulo André

jandre@quimica.uminho.pt

No passado dia 27 de novembro teve lugar no Anfiteatro A1 do Campus de Gualtar da Universidade do Minho, em Braga, uma sessão de homenagem ao Doutor Carlos Jorge Ribeiro Silva, Professor Associado do Departamento de Química (DQ), recentemente falecido. Este sentido tributo contou com a participação de cinco dezenas de depoimentos de colegas, colaboradores, amigos e estudantes, e a projeção de vários vídeos (disponíveis na página oficial de Facebook do Departamento de Química, facebook. $\mathrm{com} / \mathrm{media} / \mathrm{set} /$ ?vanity=Dep.Quimica.UMinho. pt\&set=a.3239397366172949), recordando a sua carreira profissional e os seus interesses pessoais.

Na abertura da sessão participaram o Pró-Reitor para a Investigação e Projetos, Filipe Vaz, a Presidente da Escola de Ciências da Universidade do Minho (ECUM), Manuela Côrte-Real, a Diretora do Departamento de Química, Ana Paula Esteves, a representante da organização do evento, Dulce Geraldo, a Presidente do Núcleo de Estudantes de Química, Sara Sousa, e ainda um amigo do homenageado, Manuel dos Prazeres.

Na primeira parte, dedicada ao percurso científico de Carlos Jorge Silva, tiveram lugar as intervenções de Fernando Silva, orientador da tese de licenciatura, Irene Montenegro, antiga Diretora do Grupo de Química Física e Analítica do DQ, Michael Smith, orientador da tese de doutoramento, Rita Figueira, ex-aluna de doutoramento e investigadora júnior. Todos os Centros de I\&D da ECUM quiseram associar-se à homenagem, tendo a sessão contado com os testemunhos de Fernanda Cássio (Biologia), Teresa Valente (Ciências da Terra), Luís Cunha (Física) e Rui Ralha (Matemática). Comungando de um grande sentimento de perda pela partida inesperada de um colega como o Carlos Jorge Silva, todos os membros do Departamento/Centro de Química se uniram na sua evocação, participando num vídeo que foi exibido durante a sessão.

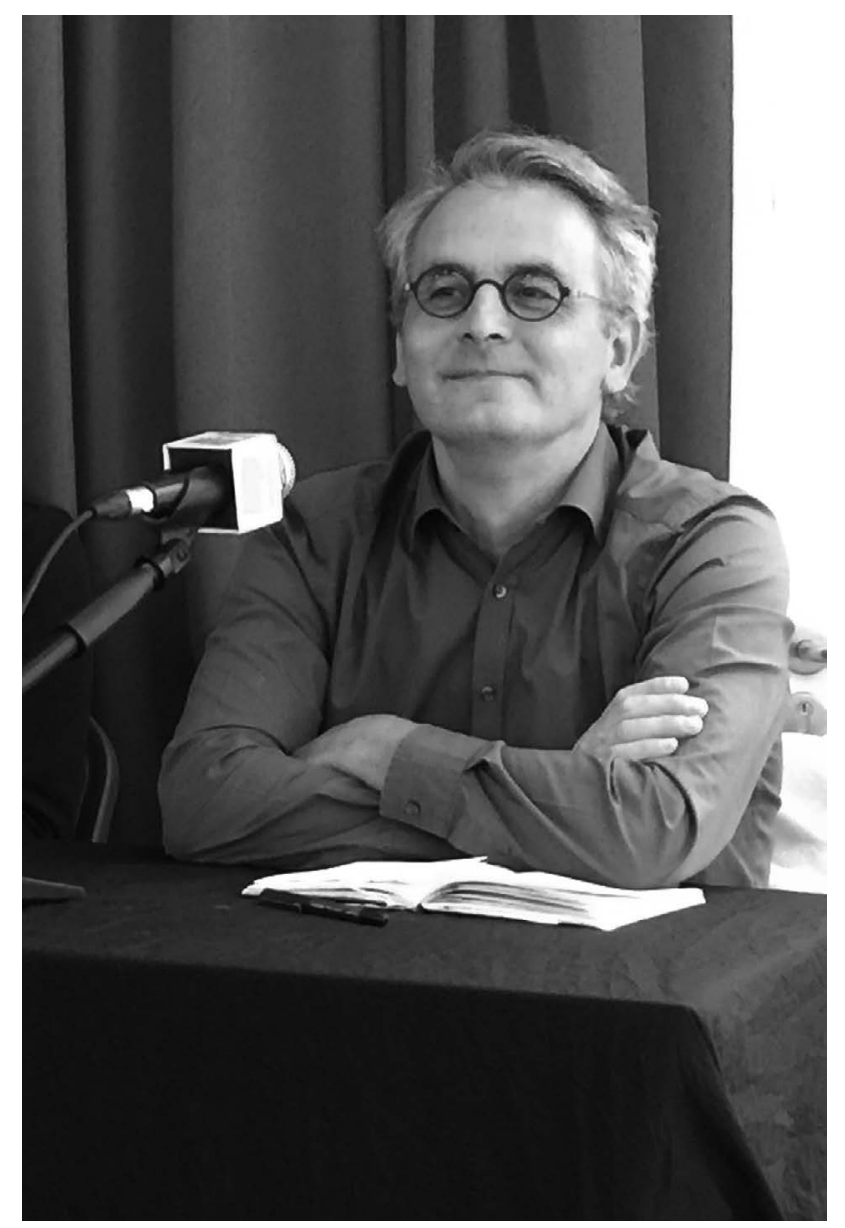

Numa segunda parte, dedicada ao percurso pessoal do homenageado, intervieram alunos e ex-alunos, Sara Sousa (Núcleo de Estudantes de Química), Cosme Moura (colega de curso), Francisco Fernandes (colaborador internacional), Jorge Barrote (Associação Aventura da Saúde) e Pedro Aguilar (Braga Rugby). Simon Ayogu, pároco da Igreja de Nogueira, fez uma alocução e ouviu-se o poema 


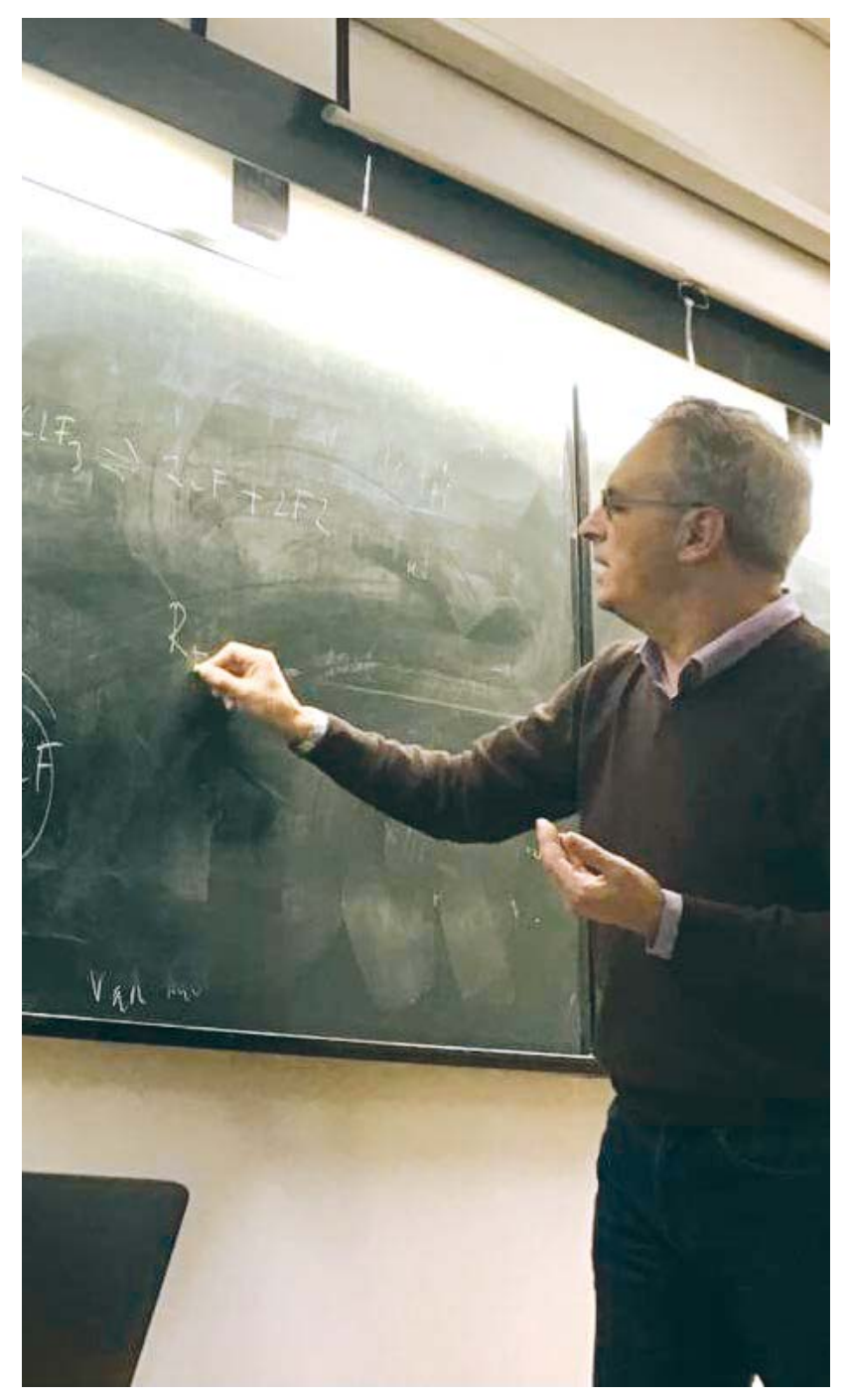

Carlos Jorge Silva numa das suas aulas

\section{6}

Os amigos não morrem: andam por aí, entram por nós dentro quando menos se espera e então tudo muda; desarrumam o passado, desarrumam o presente, instalam-se com um sorriso num canto nosso e é como se nunca tivessem partido. É como, não: nunca partiram.

António Lobo Antunes de Ruy Belo "Ácidos e Óxidos", dito pelo Sindicato da Poesia. Transmitida em streaming através do Facebook do DQ, a sessão foi seguida em países como o Vietname, Cabo Verde, Brasil e Bulgária, tendo tido mais de 4,5 mil visualizações na primeira semana (pode ser atualmente visualizado no canal Youtube do DQ youtube.com/watch?v=hKAPJ6dcNd0\&t=39s)

Inserido na semana da Ciência e Tecnologia, o tributo a Carlos Jorge Silva contou ainda com a lecionação de aulas que Ihe foram dedicadas por docentes de diferentes cursos da ECUM. Além de Diretor do Centro de Química, o Cajó - como era carinhosamente chamado -, era coordenador da linha Química Sustentável - Novos Métodos e Materiais. A sua investigação abrangia o estudo de materiais sol-gel, géis de nanopartículas de metal e semicondutores funcionalizados, revestimentos de gel e revestimentos de proteção anticorrosão.

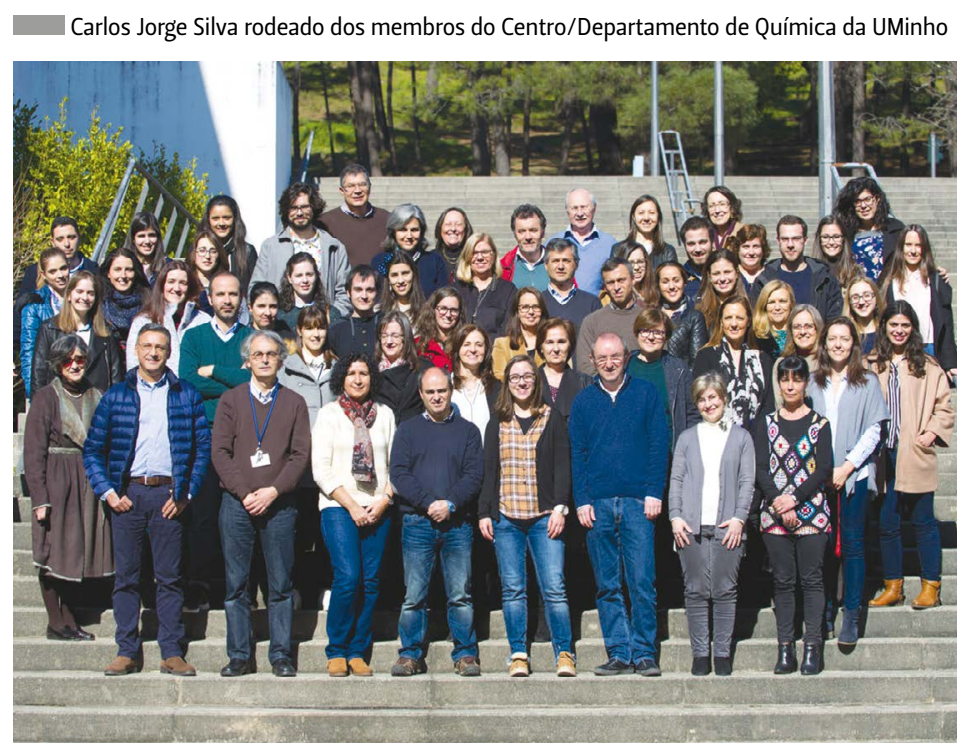

